\title{
Gender Difference in the Achievement of JHS Students Taught Selected Concepts on Matter Using Integration of Indigenous Industrial Activities
}

\author{
Richard Akwasi Frimpong \\ Science Department, Agogo Presbyterian College of Education, Agogo-Ghana \\ Charles Agyei Amoah \\ Science Department, OLA College of Education, Cape Coast-Ghana \\ Michael Ayayee \\ Ghana Education Service, Accra-Ghana
}

\begin{abstract}
This study aims at finding out the gender difference in the achievement of JHS students taught selected concepts on matter using integration of indigenous industrial activities in the Greater Accra Region of Ghana. The study employed posttest-only non-equivalent control group design of the quasi-experimental research design. The researcher employed the purposive sampling technique for this study, making up of 43 males and 47 females. The instruments used for collecting data for this research were test, questionnaire and semi-structured interview schedules. The findings from the study shows that there was no statistically significant difference in achievement between male and female students of the experimental group in post-test. This means that both males and females in the experimental group were at par on their conceptual understanding of the selected concepts on matter before and after the treatment. Therefore, in the context of this study, gender did not seem to have any influence on the achievement of the students.
\end{abstract}

Keywords: Indigenous Industrial Activities, Traditional Approach, Indigenous Knowledge, Enculturation DOI: $10.7176 / \mathrm{JEP} / 10-36-17$

Publication date: December $31^{\text {st }} 2019$

\section{Introduction}

Science embraces every attempt of humans to explore, interpret and manage the natural world. Science is also primarily concerned with the intellectualisation of facts and values in an unbiased manner (Samuel, 1996). In addition, it is dynamic and essentially concerned with the search and explanation of both regularities and irregularities in nature. Furthermore, it involves the quest for actions and reactions, and causes and effects in the environment. The purpose of science is to transform the environment towards improving the general quality of life, thus making the world a better place in which to live.

Every traditional society of the world possesses a form of science or technology which is employed in indigenous practices geared towards the satisfaction of basic needs. These informal practices may be useful even in the face of modern science and technological advancements (Ogunniyi, 1988; Samuel, 1996). Instead of rendering them obsolete in these societies, they can be refined and integrated in the knowledge and techniques of modern science. Because they constitute direct experiences with the immediate environment and with the natural world, they may be very useful to teachers and learners in enriching classroom science experiences and thereby facilitating teaching and learning.

Formal and informal sciences interact with one another. In Nigeria, both are practised in different contexts and their linkage is advocated (Mejeha, 1992; Animola, 1992; Seweje, 2000). For this tobecome a reality in Nigerian, the National Policy on Education (NPE) of 1977 categorically introduced indigenous knowledge and technologies into the curriculum from such diverse fields as traditional arts and crafts, traditional cosmetics, traditional food systems and medicine, knowledge of the environment, and African civilization (Federal Republic of Nigeria, 2004). Although this perspective may seem retrogressive considering the present pace of global scientific and technological advancement, the motive is crucial in orientating learners to perceive science as action taking place daily in the environment.

Children acquire indigenous concepts of the natural world from the communities in which they live. They also develop their own concepts and explanations about natural phenomena from the environment. Children's conceptions and views of the natural world are products of socio-cultural influences as well as individual construction (Wertsch, 1991). Science education, which is seen to directly deal with the natural world, could play a major role in shaping children's conceptions and world views. However, in the science classroom, children's indigenous conceptions and world views may sometimes be incompatible with scientific knowledge and the scientific world view. Contemporary view holds that an African is operating in two worlds when it comes to the 
learning and practising of Western Science and Technology. Based on this view, it is apparently obvious that the curriculum materials drawn out to teach science and other science related subjects to African children must have the recognition for these "two worlds".

A great concern has been raised about the fact that the teaching and learning of science in African schools has been divorced from the variety of science and technology concepts in indigenous, informal and formal industrial activities within learners' environment, of which they may have prior knowledge. Learning is a process of building on existing knowledge base. The activation of learners' prior knowledge and experiences refers to cueing the memory of concepts or ideas and situations and bringing these to the forefront to be utilised by learners (SACOST, 2008). For any effective teaching and learning to occur, the knowledge and personal experiences of learners need to be first activated.

There are a lot of indigenous industrial activities that the learner may be aware of in his or her community. Some of these are "pito and burukutu" brewing, soap making, batik making, tie and dye making, blacksmithing, shea butter or oil extraction from nuts and seeds, herbal extraction, kenkey making, beads making and leather making, to mention a few. Students see these activities or practices carried out, but never know how the processes in there are related to the science studied at school.Realising the importance of indigenous technologies in science teaching,Anamuah-Mensah (1987) advocates the integration of indigenous technologies in the teaching of science. As a consequence, a Centre for School and Community Science and Technology (SACOST) was established by African Forum for Children's Literacy in Science and Technology (AFCLIST) and nested at University of Education, Winneba Since 2000. The focus of the Centre is to promote the use of indigenous technologies in the teaching and learning of science in Ghanaian schools. Many scholars like Anamuah-Mensah (1987), George (1988), Aikenhead (1997a) and Anthony-Krueger (2010) have argued in favour of the efficacy of the use of the indigenous technologies in science teaching and learning process to improve science learning outcomes.Anthony-Krueger (2010) showed that at higher levels of Bloom's Taxonomy in the Cognitive domain (comprehension, application, analysis and synthesis) students in selected Junior High Schools in the Upper West Region of Ghana performed better in science.

\section{Statement of the Problem}

One of the ever surfacing observations made by many science teachers is JHS students' inability to perform creditably in application science questions. This does not only reflect in their class exercises and terminal examinations, but also in their performance at the Basic Education Certificate Examination (BECE). For instance the Chief Examiner's Report of BECE (2001) indicates this fact by testifying that candidates of general science were lacking the ability to apply scientific concepts and principles in solving problems.

Moreover, observations have shown that African school graduates have not been applying the knowledge they acquire from the science classroom in daily practical activities. The above observation is often seen as an attitudinal lapse, but this could be related to the indigenous conception of the African which some authors describe as being very peculiar to their own ways of life (Anamuah-Mensah, 1987). Perhaps these conceptual peculiarities are the only unique thing of the African which may account for the observed attitudinal lapse.

It is a fact that prior conceptions of learners influence teaching and learning. Studies have shown that taking accounts of pupil's prior knowledge during teaching is one of the strategies which enhance learners' ability to adapt learning to practical settings (Rivet \&Krajcik, 2002). In the African context these prior conceptions are often related to the indigenous ideas/ conceptions. However, most African science curricula systematically ignore the spectacular achievements of the African people in science (Hodson, 1993). Therefore, science taught in African schools is completely disjoined from indigenous concepts and hence teachers scarcely make any effort to alter pupils' prior conceptions to make room for functional adaptation. When children's prior conceptions are known and respected, plausible alternatives could be offered to them to make a negotiation. Hence the knowledge of children's prior conceptions from their indigenous settings can play an important role in learning outcomes.

It is equally important to note that there are many indigenous conceptions that conflict with the Western Science that is taught in African schools. According to Fafunwa (1972), and Osborne and Wittrock (1985) the conflict between these two bodies of knowledge is most likely to:

i. Make learning of science more difficult.

ii. Prevent learners from practising science concepts learnt.

iii. Affect teachers' way of teaching science concepts.

If the above are true, then this might account for learners' tendency to label science as being masculine and difficult. This psychological perception alone has a serious repercussion in learners' attitude towards science learning and application. In fact, since the African teachers themselves were taught without the appropriate alteration of their indigenous conceptions or ideas, they themselves will have some level of imbalance in their convictions with regard to scientific conceptions. This will invariably affect the way they lay emphasis on the application of the science concepts they teach. The most pressing observation in Ghana in particular is the 
existing gap between knowledge and practice/application. The activation and use of prior knowledge is therefore the first step towards any effective teaching-learning process. A study to investigate effects of teaching selected concepts on matter in integrated science using integration of Indigenous Industrial Activities at the JHS level in Ghana is therefore necessary.

\section{Purpose of the Study}

This study was designed to investigate effects of integrating indigenousindustrial activities in the teaching and learning of matter at the JHS level.

\section{Research Questions}

1. What is the difference in the achievement of JHS students taught using the integration of indigenous industrial activities in the teaching and learning of selected concepts of matter and those taught using the traditional approach only?

Ho 1: There is no significant difference in the achievement of JHS students taught selected concepts on matter using the integration of indigenous industrial activities and those taught using the traditional approach only.

\section{METHODOLOGY}

This study employed posttest-only non-equivalent control group design of the quasi-experimental research design. This research design was used because the study investigated the effect of two teaching approaches: integrating indigenous industrial activities in science teaching and the traditional approach to science teaching on experimental and control groups, which have not been equated by randomization..

In employing this design, two intact classes (Form $2^{\mathrm{A}}$ and $2^{\mathrm{B}}$ ) were used with one, as an experimental group and the other, control group. Both groups were assessed with same baseline test items in order to determine their academic standard. Form $2^{\mathrm{A}}$ class obtained the lower mean mark of 6.45 and was made the experimental group while $2^{\mathrm{B}}$ class which had the higher mean mark of 6.81 , was designated the control group. The two classes were given different treatments after which they were assessed with post-test items to ascertain the effect of the treatments. The design is further explained in the model below.

$\mathrm{O} 1 \mathrm{X} \quad \mathrm{O} 2 \quad$ Experimental group

$\mathrm{O} 1 \quad$ - $\quad \mathrm{O} 2 \quad$ Control group

The abbreviations and symbols used in the model have the following meanings:

O1 means assessment 1 (baseline test)

O2 means assessment 2 (post-test)

The symbol ' $\mathrm{X}$ ' implies treatment of integrating indigenous industrial activities in the teaching/learning of matter (experimental group).

The symbol '-' implies using the traditional science instructions in the teaching/learning of matter (control group).

The dotted line indicates that there is no random assignment of subjects to the groups.

\section{Population}

The study (accessible) population was all second year Junior High School students of Kaneshie Kingsway '2' JHS of Kaneshie Kingsway Cluster of Schools in the Okaikoi South Metro of the Greater Accra Region of Ghana.

\section{Sample and Sampling Procedure}

The researcher employed purposive sampling procedure in selecting the school for the study. The purposive sampling technique, also called judgment sampling, is the deliberate choice of subjects due to the qualities they possess. It is a non-random technique that the researcher decides what needs to be known and sets out to find subjects who can and are willing to provide the information by virtue of knowledge or experience (Bernard, 2002; Lewis \& Sheppard, 2006). However, purposive sampling can be applied to research in a number of ways, such as in preliminary studies where the researcher is still testing the feasibility of a proposed study (Poggie, 1972), sampling informants with a specific type of knowledge or skill (Prance, 2004; Vargas \& van Andel, 2005; Li, Long, Liu, Lee, Guo, Li \& Liu, 2006), comparisons of cultural practices (Neupane, Shaarma\&Thapa, 2002) etc.

Only Kaneshie Kingsway '2' Junior High School was sampled for the study. The sample for the study was two intact classes of second year $\left(2^{\mathrm{A}}\right.$ and $\left.2^{\mathrm{B}}\right)$ Junior High School students in the selected school. This was made of 43 males and 47 females. The use of second year Junior High School students was dictated by two factors. Firstly, second year students were expected to have prior knowledge on the topic 'matter' from first year. Secondly, concepts on the topic 'matter' featured prominently in the second year integrated science teaching 
syllabus (2007) and students were studying it at the time of the research.

\section{Instrumentation}

The instruments used for the collection of data in this study were test, questionnaire and semi-structured interview schedules.

Test

Two test instruments were used for the collection of data for the study. These were the baseline test and post-test. Each test instrument question was of twenty items, comprising:

$>$ ten (10) multiple-choice items;

$>$ five (5) true/false items and

$>$ five (5) short-answer/completion items.

\section{Baseline test}

A baseline test (Appendix A) was basically used to classify the two intact classes into control and experimental groups. It was administered to all participants in their respective classrooms by the researcher and the questions were based on what they were taught on the topic matter in the previous year (form one). The class that obtained the lower mean mark in the baseline test was chosen as the experimental group and that with the higher mean mark as the control group. This was to prevent the situation where any observed positive effect might be as a result of the pre-existing academic difference between the classes.

\section{Post-test}

Lessons were prepared linking indigenous industrial activities to scientific concepts by the researcher. The experimental group was then taught some selected concepts using these lessons for a period of six weeks. The selected concepts included states of matter, properties of the states of matter, change of states of matter, mixtures, separation of mixtures, metals and non-metals. The indigenous industrial activities that were integrated into the teaching of these concepts were kenkey making, gari production, blacksmithing, leather making and beads making.

The control group was however, taught the same topics using only the traditional approach to teaching and learning of integrated science for the same period by the researcher. Subjects in both experimental and control groups were then tested with a Post-test Instrument (Appendix B) - Students' Achievement in Integrated Science Test (SAIST). The outcomes of the test (SAIST) were used to answer Research Questions 1 and 2.

\section{Questionnaire}

The students' questionnaire was made up of ten (10) items (Appendix C) and, were close-ended and on a fivepoint Likert type scale. The students' questionnaire was used to find out how the integration of indigenous industrial activities in the teaching and learning of selected concepts on matter had influenced the attitude of JHS students towards the learning of integrated science.

\section{Interview Schedule}

Semi-structured interview (Appendix D) was employed as one of the main tools in this research to collect more information from the pupils. This is because, where a quantitative study has been carried out, qualitative data can be used to validate particular measures or to clarify and illustrate the meaning of the findings, and to see whether their experiences concur with the ratings on the measure (King, 1994).

The researcher interviewed twenty (20) students from the experimental group. These students were chosen at random using simple random technique and gender balance was taken into account. In all ten males and ten females were sampled for the interview. The students' interview was made up of ten (10) items. The interview formed the secondary source of data to supplement the questionnaire, which was supposed to be the primary source of data. It was used to determine whether the respondents' (students) expressed views were consistent with their questionnaire responses, and finally it assisted in interpreting and explaining the findings.

\section{Validity and Reliability of the Instrument}

Students test,questionnaire and interview were developed in consultation with peers and supervisors providing expert advice to enhance content validity of the instrument. In order to ensure that the research instruments produce scores that are stable and consistent and their test items and questionnaire items are devoid of any ambiguities (Creswell, 2008), the test items were pilot-tested at the Kaneshie Kingsway ' 1 ' JHS at Kaneshie in the Greater Accra Region which is outside the accessible population. The above school was used because it has some attributes similar to the accessible population of the study. The test items was personally administered to twenty (20) students in the pilot school and the result was analysed afterwards to determine the validity of the 
instrument and helped revise items that needed correction. But questionnaire and semi structured interview items were examined by experts in science education who had undertaken research involving classroom studies and indigenous industrial activities and some colleagues for peer review. Their responses varied in length and detail, but in general, were of a positive and supportive nature. The revised questionnaire and semi-structured interview items were then used to collect data on attitudinal changes students' exposed to teaching science by integration of indigenous industrial activities exhibit.

On the days that data were collected, the Subjects were made to understand that the questionnaire, baseline test, post-test and interview were in no way a test and that what was required of them was to answer in a sincere manner. The researcher took the respondents through the twenty items on the baseline test and post-test, and ten item questionnaire explaining and citing examples to bring home meaning to statements which seemed difficult to be understood by the respondents.

Cronbach alpha co-efficient was used to determine the reliability of the instrument after the pilot-testing. The cronbach alpha co-efficient of the baseline test was 0.838 , that of the post-test was also 0.771 , which indicates that the tests were reliable, (Appendix E). A test with a Cronbach alpha coefficient of 0.7 indicates that the test is $70 \%$ reliable in practice and any reliability co-efficient equal or greater than 0.7 is acceptable. According to Borg, Gall and Gall (1993) coefficient of reliability values above 0.75 are considered reliable.

\section{Results /Discussion}

Research Questions (1) and Ho 1

RQ 1: What is the difference in the achievement of JHS students taught using the integration of indigenous industrial activities in the teaching and learning of selected concepts of matter and those taught using the traditionally instructed classroom practices only?

Ho 1: There is no significant difference in the achievement of JHS students taught using the integration of indigenous industrial activities in the teaching and learning of selected concepts on matter and those taught using the traditional approach only.

Table 1: Frequency Distribution of Post-test Scores of Students in both the Experimental and Control Groups

\begin{tabular}{cccc}
\hline Scores & $0-9$ & $10-19$ & $20-25$ \\
\hline Experimental Group & 0 & 32 & 10 \\
Control Group & 11 & 30 & 0 \\
\hline
\end{tabular}

Source: Students' marked scripts

The result from Table 1 shows that, no student of the Experimental group scored below 10 in the post-test, 32 students scored between 10 and 19, and as many as 10 students scored above 19. In the Control group however, 11 students scored below 10, as many as 30 students scored between 10 and 19 in the post-test. None of the students in the Control group was able to score above 19 in the post-test (Table 1).

In order to find out whether there was a significant difference in the achievement of Experimental Group and Control Group in post-test, an independent measures t-Test was conducted at a 0.05 significant level.

Table 2: Determination of Significant Differences between Experimental Groups and Control Group

\begin{tabular}{|c|c|c|c|c|c|c|}
\hline Groups Compared & Test & Mean & \multicolumn{2}{|c|}{$S D t$ - value } & \multicolumn{2}{|l|}{ df $p$-value } \\
\hline Experimental Group & Post-test & 17.26 & 3.729 & 7.362 & 81 & 0.00 \\
\hline Control Group & Post-test & 11.68 & 3.142 & & & \\
\hline
\end{tabular}

From Table 2, the mean score of the Experimental Group on the post-test items after treatment was 17.26 $(\mathrm{SD}=3.729)$ and that of their counterparts in the Control Group was $11.68(\mathrm{SD}=3.142)$. These figures show that the Experimental Group had a higher mean score than their counterparts in the Control Group on the post-test items. More so, the t-Test shows that the difference in achievement of the Experimental Group and Control Group was statistically significant $[\mathrm{t}=7.362, \mathrm{df}=81, \mathrm{p}=0.00(>0.05)]$.

It was concluded that there is a statistically significant difference between the achievement of JHS students taught using the integration of indigenous industrial activities in the teaching and learning of selected concepts on matter and those taught using the traditionally instructed classroom practices only. The null hypothesis is therefore not accepted.

\section{Students' achievement in integrated science}

The results of this study revealed that there was a significant improvement in the achievement of the experimental group over the control group in the post-test (Table 2), even though the control group achieved better on the baseline test than the experimental group. However, the better achievement of the experimental group over the control group in the post-test may have resulted from the exposure of the experimental group to the integration of indigenous industrial activities in the teaching and learning of selected concepts on matter. The videos and charts (on kenkey making, leather making, beads making and blacksmithing) used during the study 
coupled with the visit to the kenkey house and the blacksmith workshop served as TLM as well as teaching and learning activities. Since the TLM and educational visits were real life situations, they assisted to reduce the level of abstraction and brought some concreteness into the teaching and learning process. These TLM and demonstration helped the students in the experimental group to visualize, conceptualize and also understand the selected concepts on matter better.

Contemporary literature has shown that recognising the social context of learning, as well as the effect of the learner's socio-cultural background in the teaching and learning of science, is of primary importance if a strong basic foundation is to be established for successful pupil achievement (Cobern, 1994). Indeed, the call appears now to be for culture-sensitive science education which probes what actually occurs in the minds and hearts of learners when they are being taught science (Solomon, 1987; Hewson, 1988). This is particularly relevant in the present circumstance in which the science education community seems to be travelling toward two destinations: understanding concept learning, and emphasising contextual science. This therefore implies that the socio-cultural factor of a learner's environment significantly affect achievement in school work (Ogbu, 1992; Jegede, 1995). Hence it is justifiable to say that to ignore these socio-cultural factors (indigenous practices) during teaching of science therefore, might mean doing a great disservice to the Ghanaian child.

\section{Conclusion}

Although the control group achieved better on the baseline-test than the experimental group, in the post-test the experimental group achieved significantly better (Table 2). This indicated that the experimental group had better conceptual understanding of concepts on matter than control group after the treatment. This means that junior high school students who were exposed to the integration of indigenous industrial activities in the teaching and learning of selected concepts on matter retained significantly more of the scientific concepts taught in the study than those who were taught using only the traditional approach.

\section{Recommendations}

Based on the findings of this study, the following recommendations were made:

Teachers should take cognizance of the fact that students' prior knowledge which they activate to begin a new lesson does not only comprise of the science concepts that have been taught previously but also includes the diverse indigenous knowledge the students learn from the society.

Teachers should try as much as possible to link science concepts they teach at school to the day to day activities students engage in at home and also the indigenous industrial activities within the society so as to make science relevant to the students. When this is done, it is hoped that it will whip-up students' interest in science, thus bring about improvement in students' achievement and attitude in science and would also encourage them to study it to the higher levels.

Science teachers should invite indigenous craftsmen, artisans etc. from the indigenous community as resource persons into the school to educate students on the processes and principles applied in some of these indigenous industrial activities in their community. This would whip up students' interest and help them to develop positive attitude towards science.

Students should be encouraged to explore their immediate indigenous environment in order to relate the science concepts they learn in the classroom to the activities they engage in the environment. This could be enhanced by giving students science projects that are related to their indigenous environment.

Teachers should be encouraged to improvise from the indigenous environment in the absence of the real TLM. This can be done by providing teachers hand books which should provide guidelines to that effect.

\section{REFERENCES}

Aikenhead, G. S. (1994). Consequences to learning science through STS: A research perspective. In J. Solomon \& G. Aikenhead (Eds.), STS Education: International perspectives on reform (pp. 169-186). New York: Teachers College Press.

Aikenhead, G. S. (1996). Science education: Border crossing into the subculture of science. Studies in Science Education, 27, 1-52.

Aikenhead, G. S. (1997a). Teachers, teaching strategies, and culture. In KEDI, Globalization of science education (pre-conference proceedings for the International Conference on Science Education) (pp.133 136). Seoul, Korea: Korean Educational Development Institute.

Aikenhead, G. S. (1997b). Toward a First Nations cross-cultural science and technology curriculum. Science Education, 8, 217-238.

Aikenhead, G. S. (1996). Science education: Border crossing into the subculture of science. Studies in Science Education, 27, 1-52.

Aikenhead, G. S., \&Jegede, O. J. (1998). Cross-cultural science education: A cognitive explanation of a cultural phenomenon. Journal of Research in Science Teaching, 1, 5-8. 
Aikenhead, G. S., \&Jegede, O. J. (1999). Cross-cultural Science Education: A cognitive explanation of cultural phenomena. Journal of Research in Science Teaching, 36 (3), 269-270.

Anamuah-Mensah, J., (1987). The Scientific Culture, the Traditional African Culture and Science Education. A paper presented at an Inter-Faculty Lecture at University of Education, Winneba.

Anamuah-Mensah, J., \&Asabere-Ameyaw, A. (2004). The Fusion of Modern and Indigenous Science and Technology: How should it be done? The African Journal of Educational Studies in Mathematics and Sciences, 2, 63-75.

Animola, R. B. (1992). Designing appropriate science \& technology curriculum for national development. In S. Oriaifo\& V. Gbenedio ( $1^{\text {st }}$ Edition). Science, Technology and Society: The Nigeria Experience. Benin City, University of Benin press.

Anthony-Krueger, C. (2010). Integrating indigenous Technology in Science as a means of povertyalleviation. A paper presented on $31^{\text {st }}$ August 2010 at the $52^{\text {nd }}$ GAST Conference at PRESEC, Legon Accra.

Bernard, H. R. (2002). Research Methods in Anthropology: Qualitative and quantitative Methods, (3rd Edition). Walnut Creek, California: Alta Mira Press.

Borg, W. R., Gall, J. P., \& Gall, M. D. (1993). Applying Educational Research: A Practical Guide. New York: Longman Publishing Group.

Cobern, W. W., \& Loving, C. C. (2001). Defining "science" in a multicultural world: Implications for science education. Science Education, 85(1), 50-67.

Cobern, W. W. (1994, January). Thinking about alternative constructions of science and Science education. A plenary presentation for the Second Annual Southern AfricanAssociation for Mathematics and Science Education Research Conference, University of Durban Westville, Durban, South Africa.

Cobern, W. W. (1996). Worldview Theory and Conceptual Change In Science Education. Science Education, 80, 579-610.

Creswell, J. W. (2008). Educational research: Planning, conducting, and evaluating quantitative and qualitative research, (3 ${ }^{\text {rd }}$ Ed.). Upper Saddle Creek, NJ: Pearson Education.

Fafunwa, A. B. (1972). Professionalization of Teaching. In A.A. Adaralegbe, (Ed), Philosophy for Nigerian Education, (88-95). Ibadan.

Gal, I., \& Ginsburg, L. (1994). The Role of Beliefs and Attitudes in Learning Statistics: Towards an Assessment Framework. Journal of Statistics Education, 2 (2), 1-18.

George, J. M. (1988). The role of native technology in science education in developing countries: A Caribbean perspective. School Science Review, 69 (249), 815-820.

Hewson, M. G. (1988). The Ecological Context of Knowledge: Implications for Learning Science in Developing Countries. Journal of Curriculum Studies, 20, 317-326.

Hodson, D. (1993). In Search of a Rationale for Multicultural Science Education. Science Education, 77, 685711.

Jegede, O. J. (1995). Collateral learning and the eco-cultural paradigm in science and mathematics education in Africa. Studies in Science Education, 25, 97-137.

Jegede, O. (1996, November). Whose Education, Whose Worldview, and Whose Framework:?An indigenous perspective on learning. A paper presented at the conference on "Pathways: Indigenous Education: Past, Present, Future," University of Southern Queensland, Toowoomba, Australia.

Jegede, O. (1997). School science and the development of scientific culture: A review of contemporary science education in Africa. International Journal of Science Education, 19, 1-20.

Jegede, O. J. (1998). The Knowledge Base for Learning in Science and Technology Education. In P. Naidoo, \& M. Savage, (Eds.), African Science and Technology into the New Millennium Practice, Policy and Priorities (pp 151-176). Kenwyn: Juta and Co. Ltd.

King, N. (1994). The qualitative research interview. In C.Cassell and G.symon, (Eds) Qualitative Methods in Organizational Research (pp. 271). London: Sage.

Lewis, J. L., \& Sheppard, S. R. J. (2006). Culture and communication: can landscape visualisation improve forest management consultation with indigenous communities? Landscape and Urban Planning, 77, 291313.

Li, S., Long, C., Liu, F., Lee, S., Guo, Q., Li, R., \& Liu, Y. (2006). Herbs for medicinal baths among the traditional Yao communities of China. Journal of Ethnopharmacology, 108, 59-67.

Mejeha, I. M. (1992). Integrative approach to science teaching: The future challenge. The Nigeria Teacher Today, 1 (2), 179-187.

NSF, (1994). Women, minorities, and persons with disabilities in science and engineering.Arlington, VA: NSF94-333.

Neupane, R. P., Shaarma, K. R., \&Thapa, G. B. (2002). Adoption of agroforestry in the hills of Nepal: a logistic regression analysis. Agricultural Systems, 72, 177-196.

Ogbu, J. U. (1992). Understanding cultural diversity and learning. Educational Researcher, 21 (8), 5-14, 24. 
Ogunniyi, M. B. (1988). Adapting western science to traditional African culture. International Journal of Science Education, 10, 1-9.

Poggie, J. J. (1972). Toward quality control in key informant data. Human Organization, 31, 23-30.

Rivet, A. E., \&Krajcik, J. S. (2002). Contextualizing Instruction: Leveraging Students' Prior Knowledge and Experiences to Foster Understanding of Middle School Science. In P. Bell, R. Stevens \& T. Satwicz (Eds.), Keeping Learning Complex: The Proceedingsof the Fifth International Conference for the Learning Sciences (ICLS). Mahwah, NJ: Erlbaum.

SACOST, (2008). Kenkey making. University of Education, Winneba, Ghana.

SACOST, (2008). Beads making. University of Education, Winneba, Ghana.

SACOST, (2008). Blacksmithing. University of Education, Winneba, Ghana.

SACOST, (2008). Leather making. University of Education, Winneba, Ghana

Samuel, I. D. W. (1996). Imperial College of Science Technology and Medicine. London University, England.

Seweje, I. O. (2000). The challenge of science teaching in Nigeria today. Journal of Educational Foundations and Management, 1 (1), 208-220.

Solomon, J. (1983). Learning about energy: How pupils think in two domains. European Journal of Science Education, 5, 49-59.

Solomon, J. (1987). Social influences on the construction of pupil's understanding of science. Studies in Science Education, 14, 63-82.

Solomon, J. (1992). Getting to know about energy. London: Falmer Press.

Vargas, M. P. B., \& van Andel, T. (2005). The use of hemiepiphytes as craft fibres by indigenous communities in the Colombian Amazon. Ethnobotany Research and Applications, 3, 243-260.

Wertsch, J. V. (1991). Voices of the mind: A sociocultural approach to mediated action. Cambridge, M. A: Harvard University Press. 